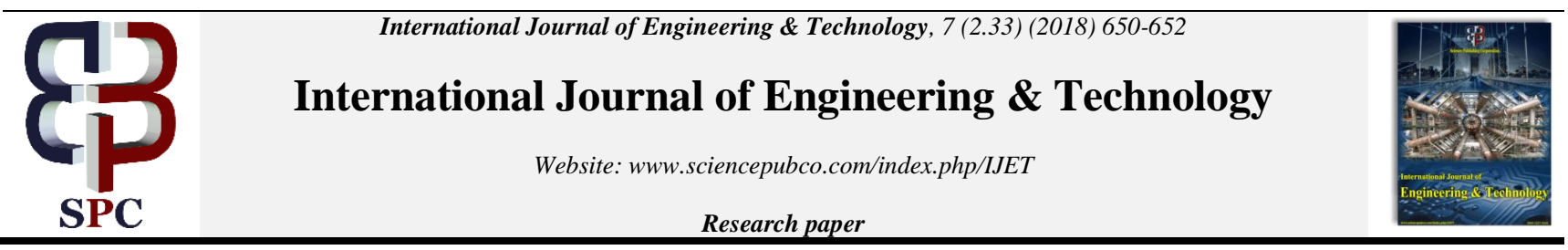

\title{
Improvement of the performance of wearable textile antenna
}

\author{
Janabeg Loni1a ${ }^{1}$, V. K. Singh ${ }^{1}{ }^{*}$, Anand Kumar Tripathi ${ }^{1}$, Gyoo-Soo Chae ${ }^{2}$, Ashis Sharma ${ }^{3}$, Akash Kumar Bhoi ${ }^{4}$ \\ ${ }^{1}$ Dept. of Electronics \& Communication Engineering, P K University, M.P. India \\ ${ }^{2}$ Division of Information and Communication, Baekseok University, Cheonan, South Korea \\ ${ }^{3}$ Sikkim Manipal Institute of Technology (SMIT), Sikkim Manipal University, India \\ ${ }^{4}$ Department of Electrical \& Electronics Engineering, Sikkim Manipal Institute of Technology (SMIT), Sikkim Manipal University, India \\ *Corresponding author E-mail: singhvinod34@gmail.com
}

\begin{abstract}
In this article low cost wearable textile receiver antenna with copper ground is proposed. The anticipated antenna has the ability to receive the frequency between $2.185 \mathrm{GHz}$ to $6.625 \mathrm{GHz}$. The antenna parameters have been improved through the optimization technique. A com-parison is studied and described among some existing and anticipated antenna. The proposed wearable receiver antenna is applicable to re-ceive radio wave energy available in the range $2.185 \mathrm{GHz}$ to $6.625 \mathrm{GHz}$.
\end{abstract}

Keywords: Jeans Substrate; CST Software; Textile Antenna.

\section{Introduction}

The material like textile is insisting due to their high flexibility, low cost, light weight, low profile. The textile materials like jean have a low dielectric constant which lowers the weight of material and also improves the bandwidth. The dielectric constant of the material is proportional to the antenna size; hence with the textile materials compact antennas are easy to be made. The properties of an antenna such as the reflection coefficient, Voltage Standing Wave Ration, antenna gain and antenna radiation pattern are studied and analyzed for antenna designing [1-5].

The various kinds of antenna that are unable to bend and made up of a copper, known as printed antenna. In the case of textile antenna the copper tape is utilized to make ground plane as well as the radiating element. Copper tape has been pasted on both sides of substrate to make radiating part and ground plane of textile antenna. The handling of flexible materials for the development of microstrip antenna has been quick because of the recent tininess of wireless devices [6-8]. The far field characteristics of antenna are also an important function, when as an application communication is established between body worn sensors and larger units such as Personal Computer, Laptop, Mobile phones and Personal Digital Assistant [9-15].

The anticipated receiver antenna can be received RF power at resonant frequency $3.76 \mathrm{GHz}$. The bandwidth and directivity of the anticipated receiver antenna is far better than some existing antennas. The presented flexible textile antenna is applicable to receive radio frequency energy available in the range $2.185 \mathrm{GHz}$ to $6.625 \mathrm{GHz}$.

\section{Wearable antenna design}

The textile antenna was simulated in CST microwave studio 2010 environment. Table 1 contains the parameters and dimensions of the simulated textile antenna. The circular patch radius is calculated by using Eq. (1).
Where

$\mathrm{f}_{\mathrm{r}}=$ resonant frequency in $\mathrm{GHz}$

$\varepsilon_{\mathrm{r}}=$ relative permittivity

$\mathrm{r}=$ radius of circular patch

The antenna designed and optimized with the CST microwave studio is depicted in Figure1. The designed antenna can be received RF power at resonant frequency $3.76 \mathrm{GHz}$.

$$
r=\frac{87.94}{f r \sqrt{\varepsilon_{r}}}
$$

(A)

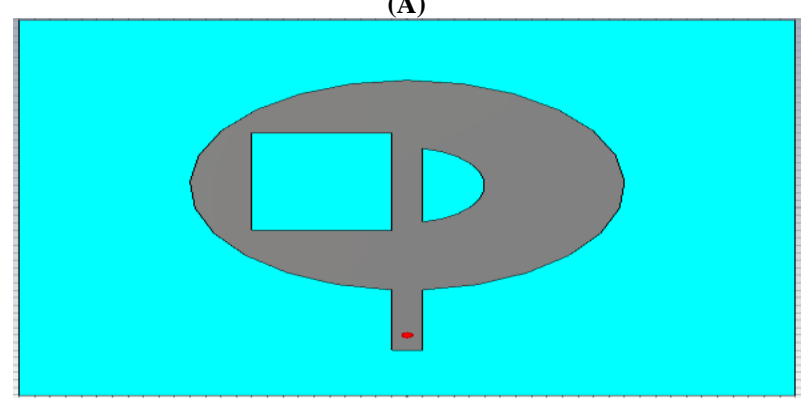

(B)

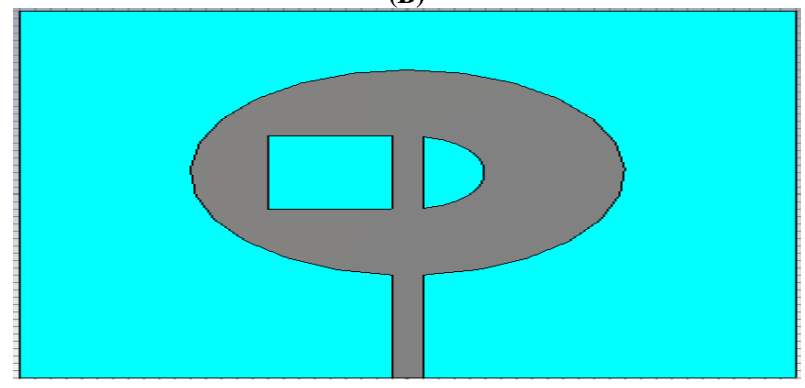


(C)

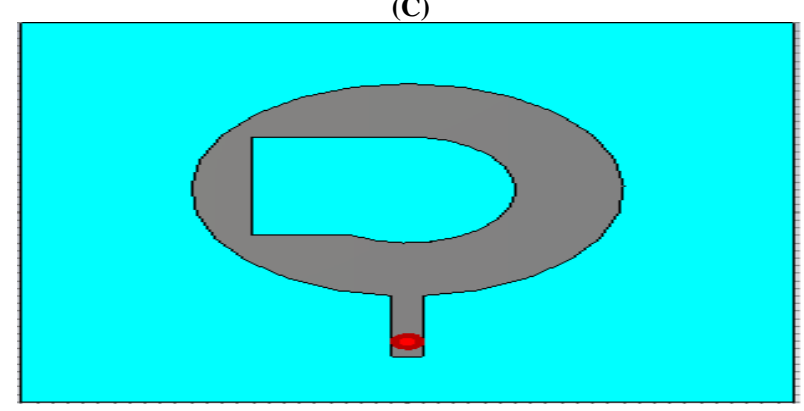

(D)

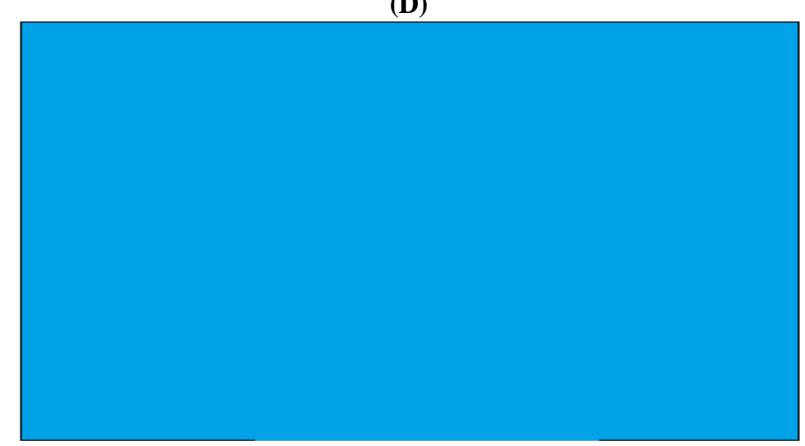

Fig. 1: Proposed Antenna Geometries (A) Antenna 1 (B) Antenna 2 (C) Antenna 3 (D) Ground Plane.

Table 1: Antenna Parameters of Receiver Antenna

\begin{tabular}{lllll}
\hline \multicolumn{5}{c}{ Table 1: Antenna Parameters of Receiver Antenna } \\
\hline Design & $\begin{array}{l}\text { Semi- } \\
\text { Circle } \\
\text { Radius } \\
(\mathrm{mm})\end{array}$ & $\begin{array}{l}\text { Substrate } \\
\text { dimension } \\
(\mathrm{mm})\end{array}$ & $\begin{array}{l}\text { Substrate thick- } \\
\text { ness }(\mathrm{mm})\end{array}$ & $\begin{array}{l}\text { Feed } \\
\text { Width } \\
(\mathrm{mm})\end{array}$ \\
\hline $\begin{array}{l}\text { Antenna- } \\
1\end{array}$ & 5 & $50 \times 50$ & 1 & 2.0 \\
$\begin{array}{l}\text { Antenna- } \\
2\end{array}$ & 5 & $50 \times 50$ & 1 & 2.0 \\
$\begin{array}{l}\text { Antenna- } \\
3\end{array}$ & 7 & $50 \times 50$ & 1 & 2.0 \\
\hline
\end{tabular}

Table 2: Antenna Substrate Dimensions

\begin{tabular}{ll}
\hline Antenna Parameters & Values \\
\hline Substrate Thickness $(\mathrm{h})$ & 1 \\
Relative Permittivity $\left(\varepsilon_{\mathrm{r}}\right)$ & 1.7 \\
Semi-circle radius[mm] & 14 \\
Rectangle width[mm] & 14 \\
Rectangle length[mm] & 10 \\
Ground Plane Dimension & $50 \times 50$ \\
\hline
\end{tabular}

\section{3. Result and discussion}

The reflection coefficient with frequency plot has been presented in figure 2 and the comparison of the reflection coefficient of different structures is presented in figure 3. Fig 4 presents smith chart Vs frequency plot of presenting receiver antenna which shows the $50 \mathrm{ohm}$ impedance at the resonant frequency. The far field pattern \& 3-D plot of the receiver antenna is given below in figure 5 and figure 6 which shows the directivity of $3.124 \mathrm{dBi}$. The value of reflection coefficient has shifted to its centre frequency by changing the slot. The bandwidth and directivity of the anticipated receiver antenna is far better than some existing antennas shown in table 2 .

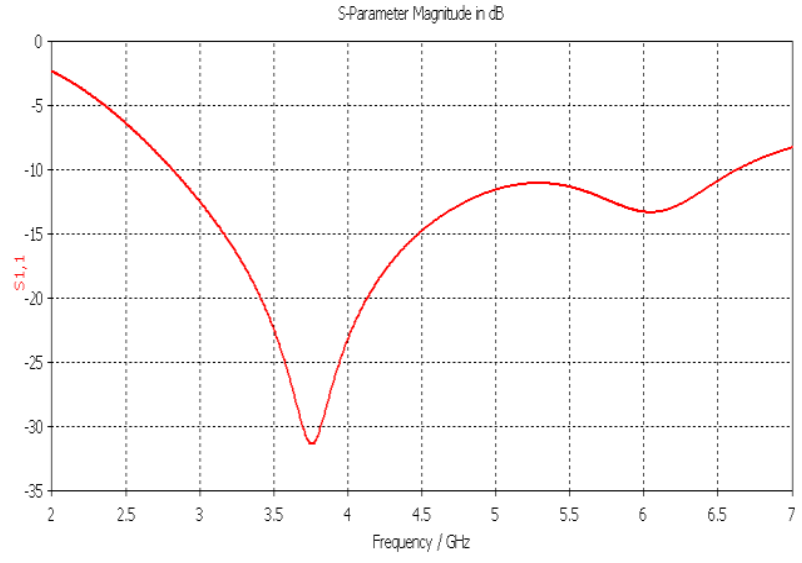

Fig. 2: Return Loss vs Frequency Plot of Proposed Antenna.

Table 3: Performance Comparison of Existing and Proposed Antenna

\begin{tabular}{|c|c|c|c|c|c|}
\hline References & Substrate & $\begin{array}{l}\text { Frequency } \\
\text { Range }\end{array}$ & Size (mm) & $\begin{array}{l}\text { Band } \\
\text { Width }\end{array}$ & $\begin{array}{l}\text { Peak } \\
\text { Gain } \\
(\mathrm{dB})\end{array}$ \\
\hline $\begin{array}{l}\text { Ling Xu } \\
{[13]}\end{array}$ & $\begin{array}{l}\text { Felt, } \\
\varepsilon_{\mathrm{r}}=2.4\end{array}$ & $\begin{array}{l}2.4- \\
2.5 \mathrm{GHz} \\
5.725- \\
5.875 \\
\mathrm{GHz}\end{array}$ & $70 \times 40 \times 3$ & $2.40 \%$ & $\begin{array}{l}2.7 \\
d B\end{array}$ \\
\hline $\begin{array}{l}\text { Marcus } \\
\text { Grilo[14] }\end{array}$ & $\begin{array}{l}\text { Denim } \\
\varepsilon_{\mathrm{r}}=1.77\end{array}$ & $2.45 \mathrm{GHz}$ & $43.3 \times 38 \times 1.4$ & $15 \%$ & $\begin{array}{l}0.78 \\
\mathrm{~dB}\end{array}$ \\
\hline $\begin{array}{l}\text { Rawat and } \\
\text { Sharma } \\
{[15]}\end{array}$ & $\begin{array}{l}\text { FR-4 } \\
\varepsilon_{\mathrm{r}}=4.4\end{array}$ & $\begin{array}{l}4.04-7.28 \\
\mathrm{GHz}\end{array}$ & $30 \times 30 \times 1.59$ & $60.30 \%$ & $\begin{array}{l}3.0 \\
\text { dB }\end{array}$ \\
\hline $\begin{array}{l}\text { Proposed } \\
\text { Antenna }\end{array}$ & $\begin{array}{l}\text { Jeans } \\
\varepsilon_{\mathrm{r}}=1.7\end{array}$ & $\begin{array}{l}2.185- \\
6.625 \\
\mathrm{GHz}\end{array}$ & $50 \times 50 \times 1.0$ & $100.90 \%$ & $\begin{array}{l}3.124 \\
\mathrm{~dB}\end{array}$ \\
\hline
\end{tabular}

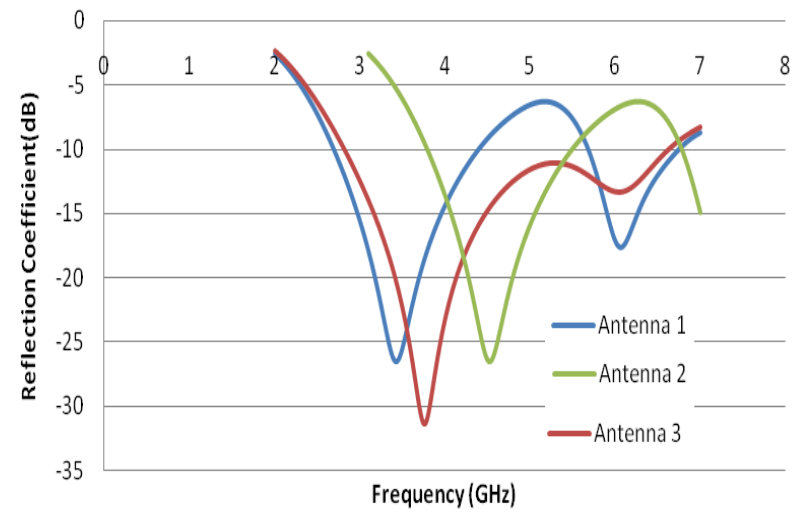

Fig. 3: Reflection Coefficient vs Frequency Plot through Optimization

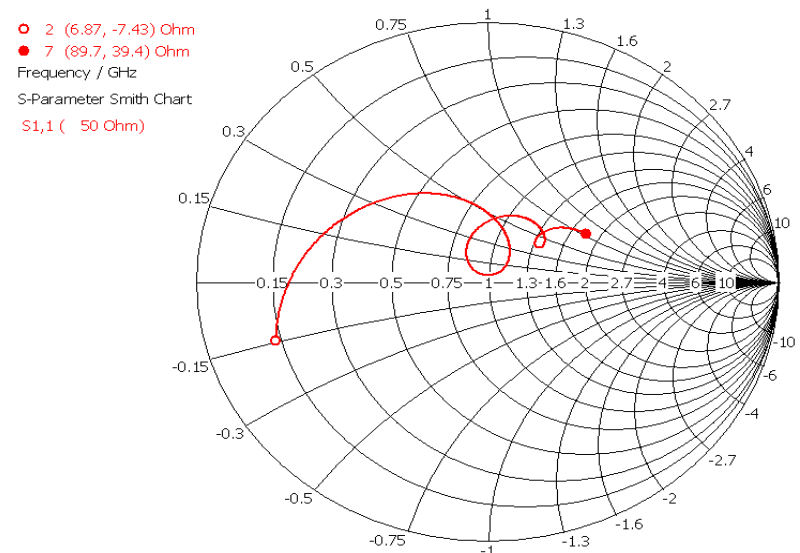

Fig. 4: Smith Chart vs Frequency Plot of Presented Receiver Antenna 


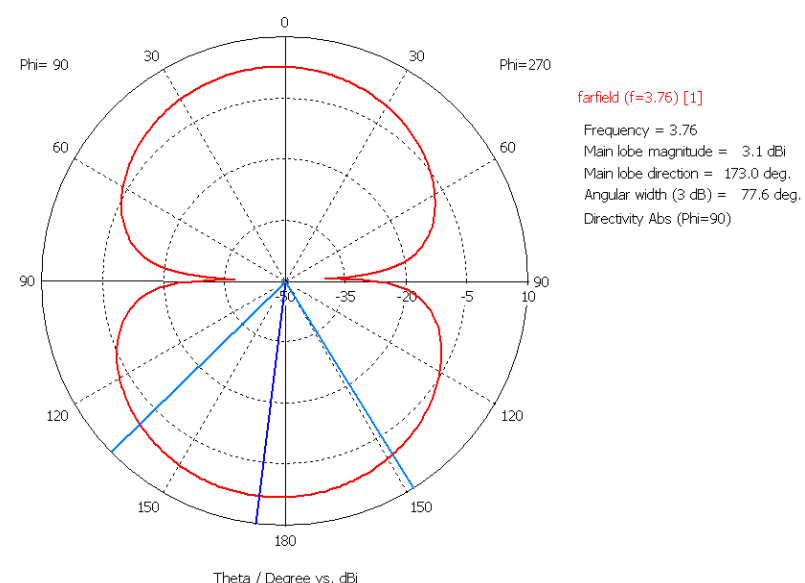

Fig. 5: Far Field Pattern vs Frequency Plot of Presented Antenna

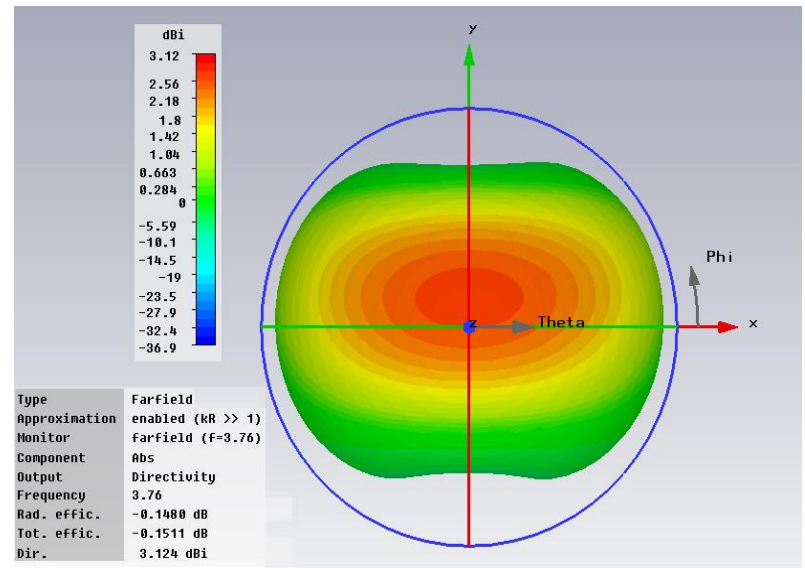

Fig. 6: Far Field 3-Dimensional Radiation Pattern Showing Directivity of Proposed Receiver Antenna.

\section{Conclusion}

An optimized low cost wearable textile receiver antenna is designed, simulated using jeans substrate. Simulation results have carried out by using CST simulation software. The antenna has covered the frequency range from $2.185 \mathrm{GHz}$ to $6.625 \mathrm{GHz}$ having very large bandwidth of $100.90 \%$. The designed receiver antenna can be received RF power at resonant frequency $3.76 \mathrm{GHz}$. The bandwidth and directivity of the anticipated receiver antenna is far better than some existing antennas.

\section{References}

[1] T.C. Yo, C. M. Lee, C. M. Hsu, and C.-H. Luo, "Compact circularly polarized rectenna with unbalanced circular slots", IEEE Transaction on Antennas Propagation, Vol. 56, No. 3, (2008), pp: 882886.

[2] Y.H. Suh and K. Chang, "A high-efficiency dual-frequency rectenna for 2.45-and 5.8-GHz wireless power transmission" IEEE Trans. Microwave Theory Technology, Vol. 50, No. 7, (2002) pp: 17841789 .

[3] W. C. Brown, "The history of power transmission by radio waves", IEEE Trans. Microwave Theory Technology, Vol. 32, No. 9, (1984), and pp: $1230-1242$.

[4] R. Vyas, H. Nishimoto, M. Tentzeris, Y. Kawahara, and T. Asami, "A battery-less, Energy harvesting device for long range scavenging of wireless power from terrestrial TV broadcasts", IEEE MTTS Int. Microwave Symp. Digest, (2012), pp: 1-3.

[5] J.Y. Park, S.M. Han, and T. Itoh, "A rectenna design with harmonic rejecting circular-sector antenna", IEEE Antennas Wireless Propagation Letter, Vol. 3, No. 1, (2004), pp: 52-54.

[6] M. Pinuela, P. D. Mitcheson, and S. Lucyszyn: Ambient RF energy harvesting in urban and semi-urban environments, IEEE Trans. Microwave Theory Technology, Vol. 61, No. 7, (2013), pp: 27152726 .
[7] A. Georgiadis, G. Andia, and A. Collado, "Rectenna design and optimization using reciprocity theory and harmonic balance analysis for electromagnetic energy harvesting", IEEE Antennas Wireless Propagation Letter, Vol. 9, (2010), pp: 444-446.

[8] H. Sun, Y.-X. Guo, M. He, and Z. Zhong, "Design of a high efficiency $2.45 \mathrm{GHz}$ rectenna for low input power energy harvesting, IEEE Antennas Wireless Propagation Letter, Vol. 11, (2012), and pp: 929-932.

[9] C. A. Balanis, "Antenna theory: analysis and design", John Wiley \& Sons, (2012).

[10] V. K. Singh, Shorav Khan, Anil Verma, Ashish Vishnoi, Rajesh Tiwari, "Textile Antenna for Wireless Health Monitoring System Applications", International Journal of Control Theory and Application, Vol. 10, Issue 8, (2017), pp: 487-493.

[11] Rashmi Singh, Vinod Kumar Singh, Nikhil Kumar Singh, "Wide Band and Miniaturized Partial Ground Plane Microstrip Antenna for X \& Ku Band Applications", International Journal of Control Theory and Application, Vol. 10, Issue 8, (2017), pp: 477-486.

[12] Rawat, S., \& Sharma, K. K., "A compact broadband microstrip patch antenna with defected ground structure for C-band applications", Central European Journal of Engineering, Vol. 4, Issue 3, (2014), and pp: 287-292.

[13] Ling Xu, Joshua Le-Wei Li, "A Dual band Microstrip Antenna for Wearable Application", IEEE (ISAPE) conference proceeding, (2012), pp: 109-112.

[14] Marcus Grilo, Fatima Salete Correra, "Rectangular patch antenna on textile substrate fed by proximity coupling", Journal of Microwaves, Optoelectronics and Electromagnetic Applications, Vol. 14, (2015), pp 103-112.

[15] Rawat, S., \& Sharma, K. K., "A compact broadband microstrip patch antenna with defected ground structure for C-band applications", Central European Journal of Engineering, Vol. 4, Issue 3, (2014), and pp: 287-292. 